\title{
KNOX METROPOLITAN CHURCH BELL TOWER RESTORATION PROJECT
}

\author{
JUNE BOTKIN \\ Botkin Historic Building Conservators Ltd., Canada
}

\begin{abstract}
The purpose of this conservation project was to perform masonry repairs including selective repointing, stone repairs and masonry cleaning, to the upper 50 feet of the bell tower. The erection of engineered scaffolding was required to reach the designated work area allowing for a safe, comfortable working environment. Many of the mortar joints on the North and East faces of the tower had lost most of the front point mortar. This exposed the condition of the interior of the wall cavity indicating that the bricks had not been properly bedded. The project ended up including the discovery of some of the impacts of the tornado from June 30, 1912 and the rebuilding of the church after this catastrophic event. These details were photo-documented prior to the commencement of any conservation work.
\end{abstract}

Keywords: church, bell tower, Regina, tornado, mortar, Indianan Limestone, hydrated lime, King Mortar.

\section{INTRODUCTION}

Knox Metropolitan Church is constructed of red clay lime bricks with Indiana limestone architectural accents. The original design of the church by Toronto, Ontario architects Darling and Pearson was built in 1906-1907 at a cost of \$100,000. On June 30, 1912, the church sustained significant damage when an F4 tornado with wind speeds of $800 \mathrm{~km} / \mathrm{h}$ (500 mph) destroyed an estimated eighty percent of the building fabric (see Fig. 1). This tornado remains the deadliest in Canadian history killing 28 people, injuring hundreds and leaving 2500 people homeless. The tornado had a width of $150 \mathrm{~m}$ (490 feet) and traveled 30 km (19 miles) before dissipating.

"Regina's Mayor Peter McAra recorded an odd bit of damage done near the Legislative Building. To help with the building's construction, a railway spur line had been constructed in front of the structure. According to the mayor, "The most freakish things happened in the cyclone and one was the complete disappearance of the cement from eight freight cars located on the tracks at the Parliament buildings. This was found plastered on the ruins of the Metropolitan Church [on Lorne Street and Victoria Avenue, approximately one kilometer north]” [1].

"The Leader described the damage to this building as "the most complete wreck of all." The main entrance and a small portion of the wall is all that remains of the front of the building. The south wall and extension is gone except for about eight feet of bricks. This building will have to be entirely rebuilt" [2].

Following this horrific event, the church, under the supervision of Francis Henry Portnall, was redesigned and rebuilt in the style in which it appears today. The quality of the workmanship during the rebuild and the required reuse of damaged building materials is what led to the present-day masonry conservation project undertaken on the top $15 \mathrm{~m}$ (50 feet) of the bell tower. 


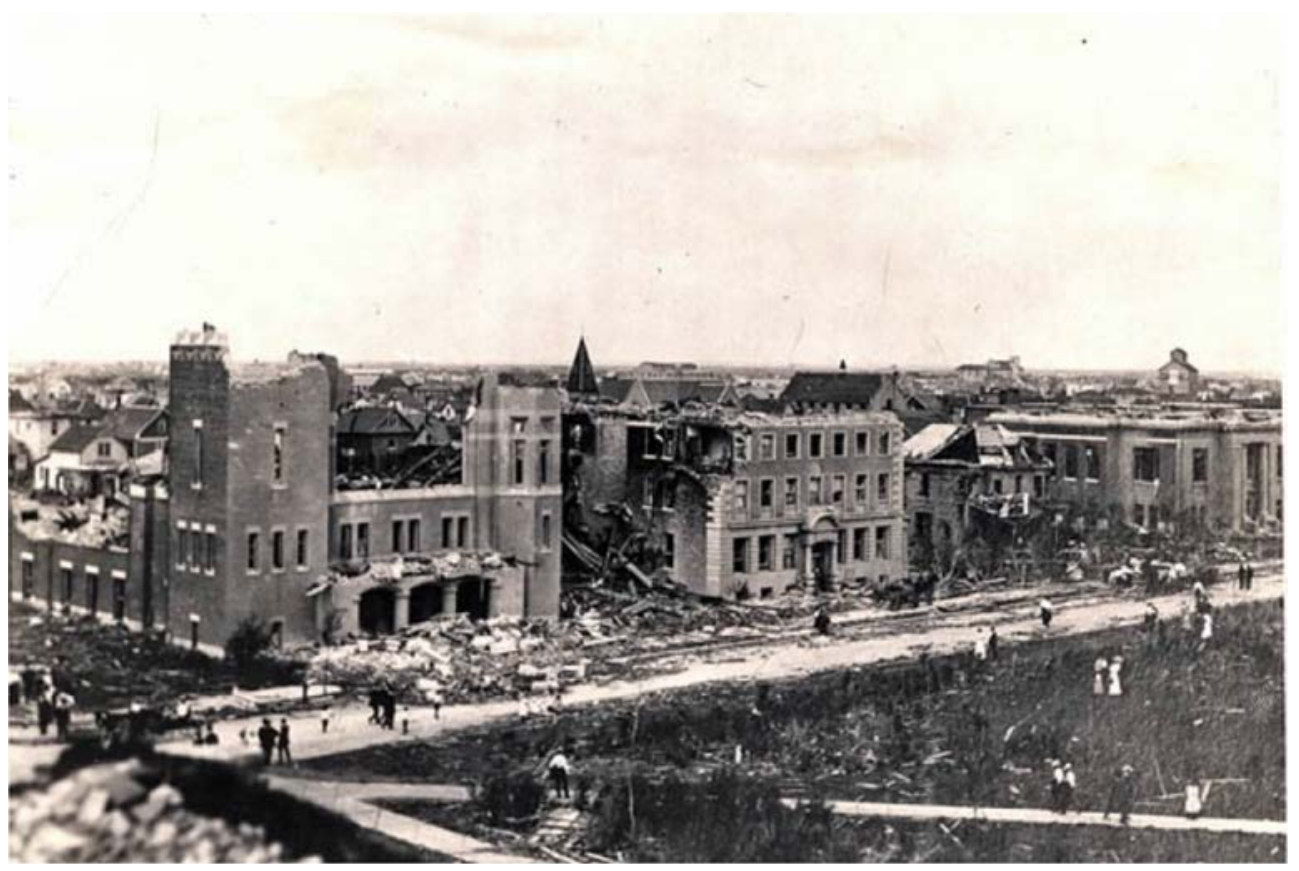

Figure 1: Destruction of Metropolitan Methodist Church and buildings along Lorne Street 1912.

\section{VISUAL INSPECTION, PHOTO DOCUMENTATION, SCOPE DEVELOPMENT AND TESTING}

The project began with a visual inspection of the bell tower, noting overall condition of the masonry units and mortar, staining (efflorescence), modern interventions and the presumed areas of deterioration. The upper $15 \mathrm{~m}$ (50') of the south and east faces could only be viewed from the ground or from the battlement looking down. The upper portions of the North and West faces could be viewed from an intersecting roof. Multiple site visits were required to confirm site conditions. Throughout the process a Nikon digital SLR camera was used to document project details. Mortar samples were taken from inside the bell tower so that various masonry tests could be undertaken. A brick was also removed to determine compressive strength as it related to the compressive strength of the mortar.

The testing process included Petrographic Analysis and x-ray diffraction analysis, hydrochloric acid testing and compressive strength testing.

The petrographic testing revealed that the binder was a Portland Cement based mortar which was strongly carbonated. Why the mortar had become so carbonated was not determined. The porosity of the sample was heterogeneously distributed in the two samples These results were very surprising as manual scraping of the mortar joints around the building indicated that the mortar was extremely soft and easily removed and crushed between fingers. The initial assumption made was that the mortar was primarily hydrated lime. Because the Petrographic Analysis did not match the working hypothesis, it was determined that another mortar sample should be taken and a hydrochloric acid analysis performed to determine the mortar mix. Hydrochloric acid testing indicated the presence of a very fine sand with pieces of clay brick. The recommended mix from this test was one part white cement, two parts 
hydrated lime and nine parts sand. This became the mix ratio for the mortar to be used for back and front pointing throughout the project.

The final set of testing involved determining the compressive strength of the existing bricks and testing a possible replacement brick from a building constructed in 1912. Two bricks were removed from two separate locations within the proposed work area. One brick was removed from the interior of the bell tower and one brick was removed from the exterior north face of the parapet. The proposed replacement brick came from Connaught School, a historic school built in 1912 and demolished in 2014. The test results are shown in Table 1.

The analysis of the bricks indicated that the bricks from Knox Met were quite soft and the recommended replacement brick from Connaught was slightly harder. The slight difference in compressive strength was not significant enough to be of concern.

\section{SCOPE DEVELOPMENT, DRAWINGS, SPECIFICATIONS AND TENDER}

With the masonry test results in hand, the scope of work for this project could be completed. The delivery method would be an invitational tender with the components of work bid on listed as individual unit prices. This would allow for competitive bidding and ensure all contractors were bidding on the same scope of work. No original drawings of the church could be found. As a result, as-built measured drawings were created along with the specifications detailing the requirements for the various masonry interventions and contract requirements including bonding and insurance. A significant cost to the project was the requirement for an engineered scaffold to meet Occupational Health and Safety Regulations of the Province. The contract was awarded to a local second generation masonry contractor from Regina for a value of $\$ 262,847$.

\section{SCAFFOLDING, SCOPE REVIEW AND VERIFICATION}

The engineered scaffold was constructed using systems scaffolding (see Fig. 2). The scaffolding components were kept $100 \mathrm{~mm}-150 \mathrm{~mm}$ (4"-6") away from the face of the building to prevent any damage from occurring to the masonry units. The required vertical tie-ins every $4000 \mathrm{~mm}$ (13') required putting the scaffold standards under tension in two directions without piercing the brick faces. Deck heights were placed at $2000 \mathrm{~mm}$ (6'6”) and were designed to accommodate workers weighing $113.4 \mathrm{~kg}$ (250 lbs) each with six people maximum/tower with, $11 \mathrm{~kg}$ (25 lbs) of tools and a material allowance of $122 \mathrm{~kg} / \mathrm{m}^{2}$ (25 psf)/tower distributed evenly.

Table 1: Brick compressive strength results.

\begin{tabular}{|c|c|c|c|}
\hline Compressive & Interior Bell Tower & Exterior Parapet & Connaught 1912 \\
\hline Sample 1 & 31.4 MPA & 29.0 & 43.2 \\
\hline Sample 2 & 30.4 & N/A & 46.3 \\
\hline Compressive average & 30.9 & 29.0 & 44.8 \\
\hline \multicolumn{4}{|c|}{ The recommended replacement brick from Connaught } \\
\hline Color & Red & Red & Red \\
\hline Size sample 1 & $101.5 \mathrm{~L} \times 94.5 \mathrm{~W} \times 65.6 \mathrm{H}$ & $91.26 \mathrm{~L} \times 82.5 \mathrm{~W} \times 65.5 \mathrm{H}$ & $95 \mathrm{~L} \times 93 \mathrm{~W} \times 65 \mathrm{H}$ \\
\hline Size sample 2 & $97.3 \mathrm{~L} \times 91.6 \mathrm{~W} \times 65.7 \mathrm{H}$ & N/A & $96 \mathrm{~L} \times 92 \mathrm{~W} \times 64 \mathrm{H}$ \\
\hline
\end{tabular}




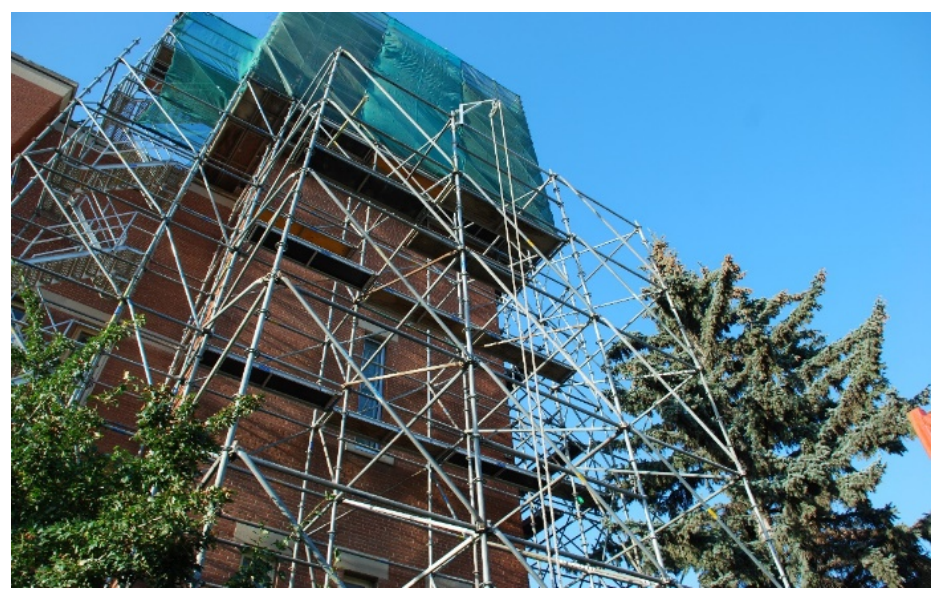

Figure 2: Scaffolding tower.

Access to the working levels was gained by use of a stair tower. Material was moved from the ground to the roof level by an electric winch with a lifting capacity of $272 \mathrm{~kg}$ (600 lbs). The upper working levels of the scaffold were accessed via an internal ladder. Tools and materials were moved onto the working levels via a manual gin wheel.

The entire upper $15 \mathrm{~m}$ (50") of the scaffold was enclosed with a heavy nylon mesh to prevent debris from falling to the ground. With the scaffolding in place, a detailed review of all the faces of the bell tower could be inspected.

It was found that the amount of missing front point mortar and bedding mortar was more significant than originally thought (see Fig. 3 ). This meant that the building would require a complete repoint instead of performing selective repointing on each of the building faces as was first presumed. The condition of the stones was also confirmed and an area for demonstration work for each component of the masonry work being completed was chosen.

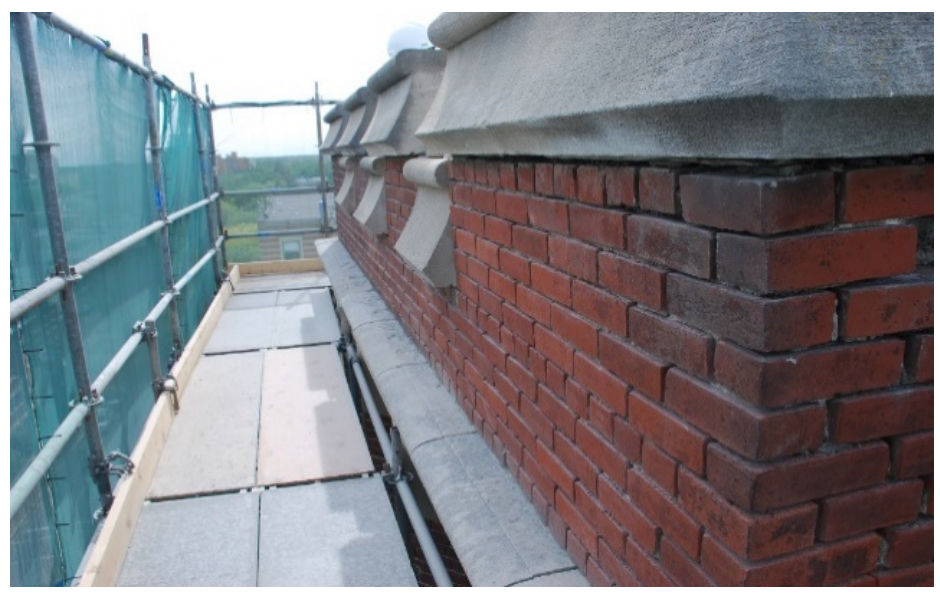

Figure 3: Masonry condition at parapet. 


\section{QUALITY CONTROL}

The contractor was required to provide written procedures, including cutting out, preparation and mortar mixing, back and front pointing as well as listing the tools he would be using during each process. The reasoning behind this was to ensure the contractor's individual masons were pre-qualified to perform the various stages of the work. The demonstration area would also act as the quality control standard. All work undertaken on each of the faces of the tower would be compared to the demonstration area for compliance in process and quality workmanship. This ensured uniform delivery of the work by all site masons.

\section{THE WORK}

Cutting out was undertaken using an Arbortech brick and masonry saw, side grinder with zero clearance $3 \mathrm{~mm}$ (1/8”) diamond cutting wheel and hand chisels. The mortar joints were measured and found to be consistently $9 \mathrm{~mm}$ (3/8”) around the building. Head joints were cut out using hand chisels. This consistency made the use of this equipment acceptable. The faces of the bell tower had all mortar removed to a depth of $25 \mathrm{~mm}$ (1"). This depth allowed for two lifts of mortar to be installed and ensured proper curing to the full depth of the removed joint. Both the inside and outside faces of the parapet were repointed completely. The inside face showed significant loss of pointing mortar as this area is exposed to the elements and can experience multiple freeze thaws cycles within a day because of the chimney effect of hot moist air rising through the interior of the bell tower and out the partially covered top.

The bricks within the work area showed evidence of impact marks across their faces. In some locations, the top of the cornice stones were heavily pitted (see Fig. 4). This was a result of the stones being hurdled across the park during the tornado and because of how and where they were reinstalled during the rebuilding process.

The length of these stones also became inconsistent. Along the west face, multiple cornice stones were measured and found to be less than $381 \mathrm{~mm}$ (15”) in length which created multiple mortar joints between the stones. These anomalies were believed to be caused by the stones being badly damaged and broken during the tornado which required them to be dressed into smaller usable lengths.

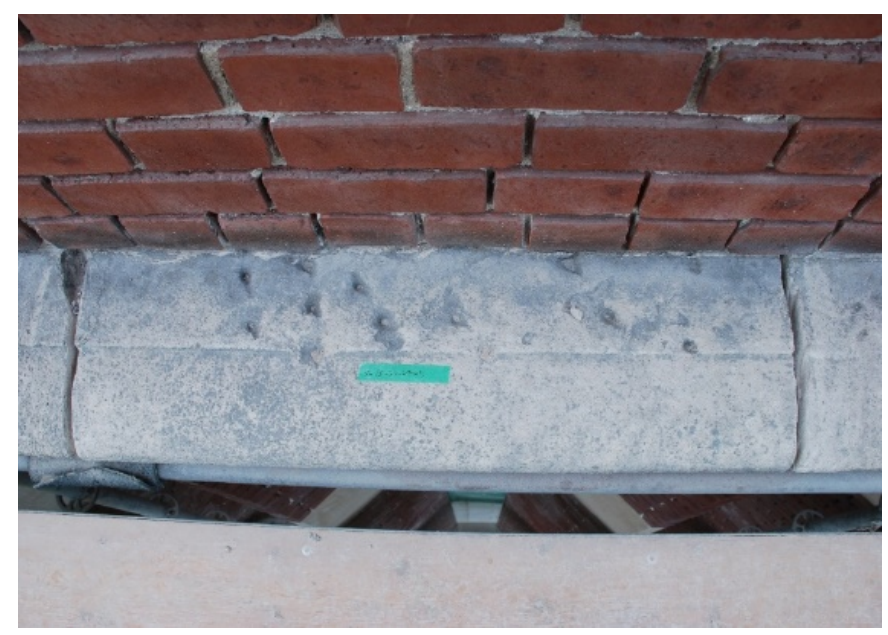

Figure 4: Pitted cornice stone. 
The string course wrapping the building at the top of the Louver's had numerous Dutchman repairs where the stone had not been properly seated in the repair pocket. In some locations where a large stone would have originally been placed, smaller stones were set and carved to replicate the original features. This would have also been the result of damage to the stones during the tornado and the requirement to dress the stone to a useable size. In one case this was not possible and, as a result, a bowl on the north face of the tower was only partially carved and hidden from view (see Fig. 5).

This partially carved stone allowed for the continuity of the brick coursing to be carried around the building face and remain consistent throughout the rebuild.

Due to the many anomalies found around the building the archivist with the City of Regina was contacted. She was able to provide some photographs of the church from this time period. The exact dates of the photographs were not known but it was determined after review of the existing design features that the church had not been rebuilt in its original form, and the full impact of the tornado of 1912 started becoming evident. It was discovered by photographic comparison that the top of the bell tower had been rebuilt in a crenellated fashion. The original design for the top of the bell tower had the capstones placed all on the same plain. Further investigation and photographic analysis indicated that many of the original design features had changed.

The large windows inserted in the upper gable ends on the north, south and east faces had been recreated in a different design style. The original windows were segmentally headed with three sets of three glazing units separated by brick pilasters. Below the main window were three pairs of smaller rectangular windows each with an Indiana limestone lintel. The sill extended across the face of the building (see Fig. 6).

The church's windows, as they appear today, appear to be designed using the Gothic style with slender tracery which separated the five main central glazing units where the upper window section which is divided in half creating ten glazing units. The original three pairs of rectangular windows were incorporated into the significantly larger windows and eliminated in the new design (see Fig. 7). String courses that were an original part of the 1906 design were removed. Pilasters with gable caps were removed and the domed north east tower was modified to obscure the prominence of dome cap at this location. The main front entrances' wood frame, cedar shake roof was removed and a balcony with a concrete slab roof was created with a decorative parapet.

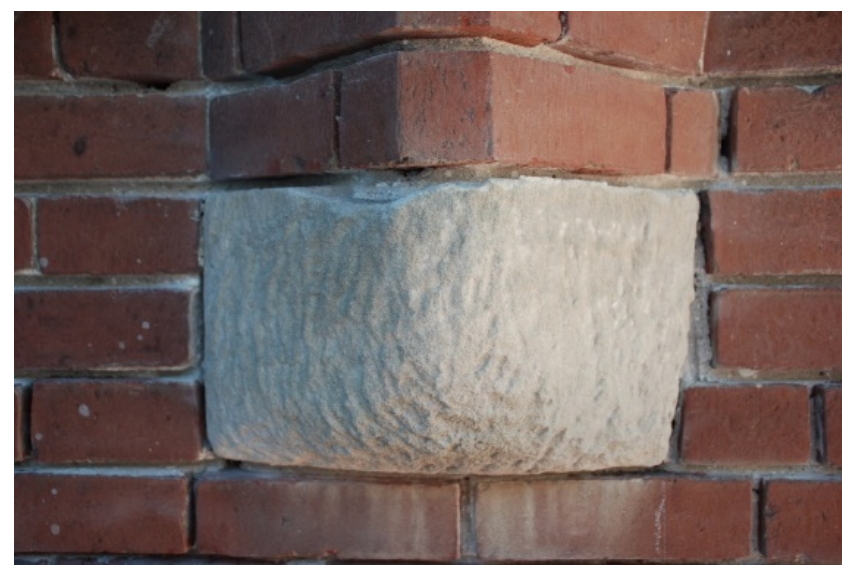

Figure 5: Partially carved bowl. 


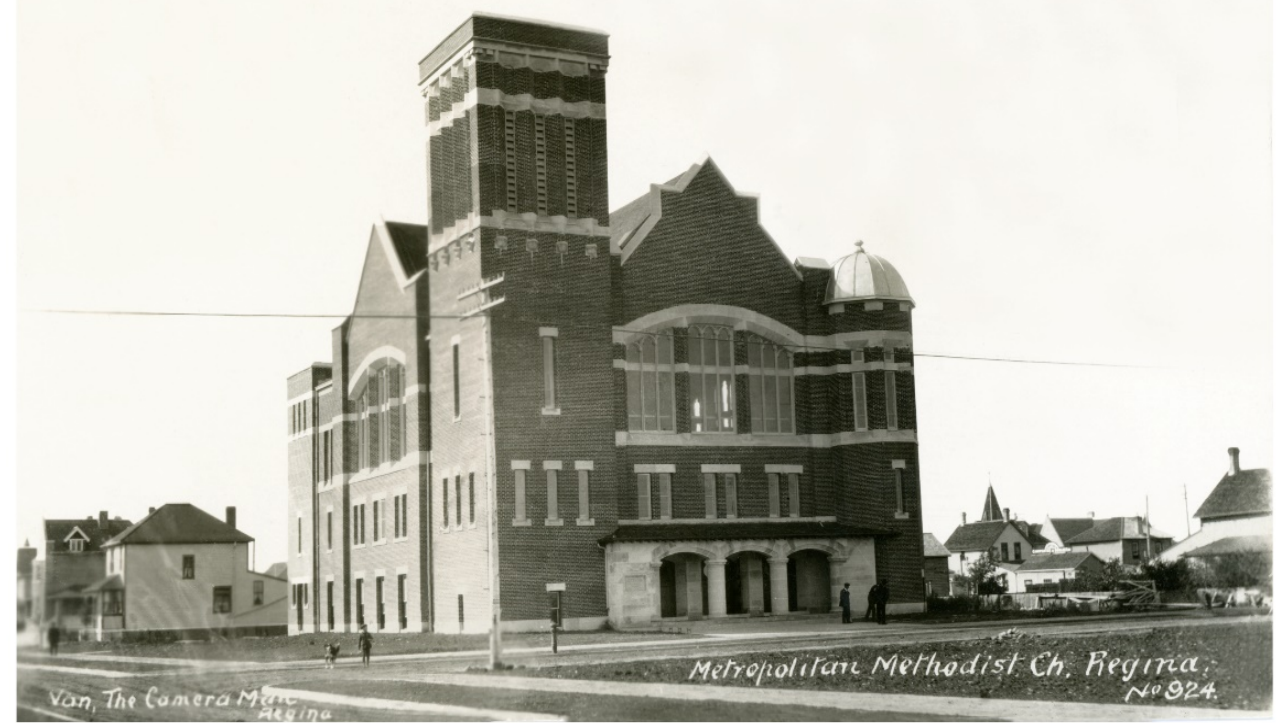

Figure 6: Metropolitan Methodist Church looking West, circa 1907.

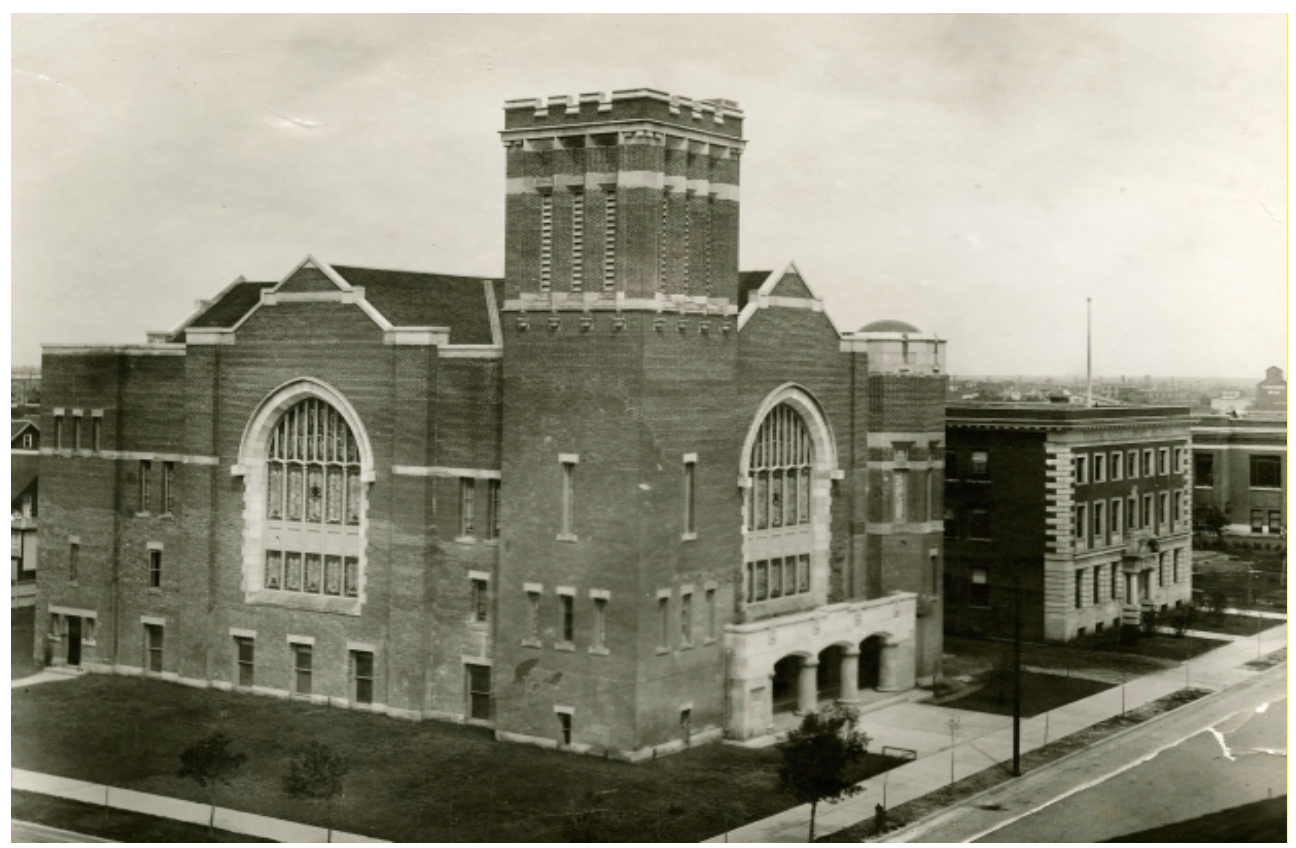

Figure 7: Metropolitan Methodist Church looking North-west, circa 1914. 
Following the guidelines outlined in The Conservation of Historic Places in Canada, 2nd edition, the decision was made to leave the bulk of the impact marks in the stone and brick untouched. The Dutchman repairs completed in 1912 were left untouched as well. One Dutchman on the string course running along the bottom of the Louvres on the east side was replaced because an iron cramp holding the stone repair in place had become saturated with water causing rust jacking and spaulding. The cramp was carefully removed and a rust inhibitor applied to the iron cramp parts left in-situ. A new $6 \mathrm{~mm}(1 / 4)$ ") stainless steel threaded rod was drilled into the stone backer and epoxied in place. The stone replacement also had an $8 \mathrm{~mm}$ (5/16") hole drilled into it which was filled with epoxy and set into the repair pocket. The hole was made $2 \mathrm{~mm}$ (1/16") larger than the stainless-steel dowel to allow for expansion of the epoxy without damaging the stone. The stone was bedded in JAHN M70 restoration mortar and the joint line around the Dutchman finished flush with the surrounding stone surfaces.

JAHN M70 was also used to fill chips, recreate edges on stones throughout the work area and fill joint lines around the existing Dutchmen where the mortar had failed and was missing.

The pointing mortar specified was a King mortar, Masoncare 1258. This is a pre-packaged mortar which was custom colored to match as closely as possible to the existing color of the limestone and original mortar. A pre-bagged mortar was chosen because the consistency and quality of the mortar could be maintained throughout the project. The contractor was not allowed to re-temper the mortar once it was mixed and could only prepare a batch of mortar that could be used within one hour of mixing. The temperature within the scaffolding had to be maintained above $10^{\circ} \mathrm{C}$ during the pointing process. The final lift of mortar (front point) was cured to fingernail hardness prior to final tooling. The mortar was then wet-cured for 3-7 days using burlap sheets hanging $100 \mathrm{~mm}$ (4”) from the face of the masonry units.

The repointing began in late fall, as a result, insulated tarps and propane heaters had to be installed within the construction area. Daytime temperatures were fluctuating between $-3^{\circ} \mathrm{C}$ $\left(26.6^{\circ} \mathrm{F}\right)$ and $-28^{\circ} \mathrm{C}\left(-18.4^{\circ} \mathrm{F}\right)$ during the month of November when the repointing work was happening. The interior temperature of the scaffolding had to be maintained at a minimum of $10^{\circ} \mathrm{C}\left(50^{\circ} \mathrm{F}\right)$.

Once the masonry repairs were $100 \%$ completed, the stones were cleaned using soda blasting. The purpose of the cleaning was to remove organic growth and atmospheric staining that had accumulated over the last 100 years. Soda blasting was chosen because of its minimal impact on the soft limestone and environment. The residue from this intervention would also be easy to clean up as part of demobilization.

Cleaning was undertaken over two days; November 18 and 19, 2016 with temperatures below $-6^{\circ} \mathrm{C}\left(42.8^{\circ} \mathrm{F}\right)$. Due to these temperatures, the lowest pressure that could be reached safely was 22 psi. On day 1 , the parapet had been cleaned and the level below had just been started. The west face of the cap stones along the top of the parapet proved problematic to clean. This was partly because of the weather affecting the equipment and partly because of the location. After the initial cleaning, further cleaning was required to remove wand marks and black staining without damaging the patina of the stone. Another problem area proved to be the underside of the dentals below the cornice (see Fig. 8).

Due to water runoff down the face of the dentals, some areas were stained black. It was impossible to remove all the staining without causing permanent damage to the stones so it was decided to leave the residual staining as it would appear as a shadow from the ground. A small area of brick was also cleaned as a test to remove lime stains resulting from repointing. The lime stains were caused by an unexpected thunderstorm where the wet mortar 


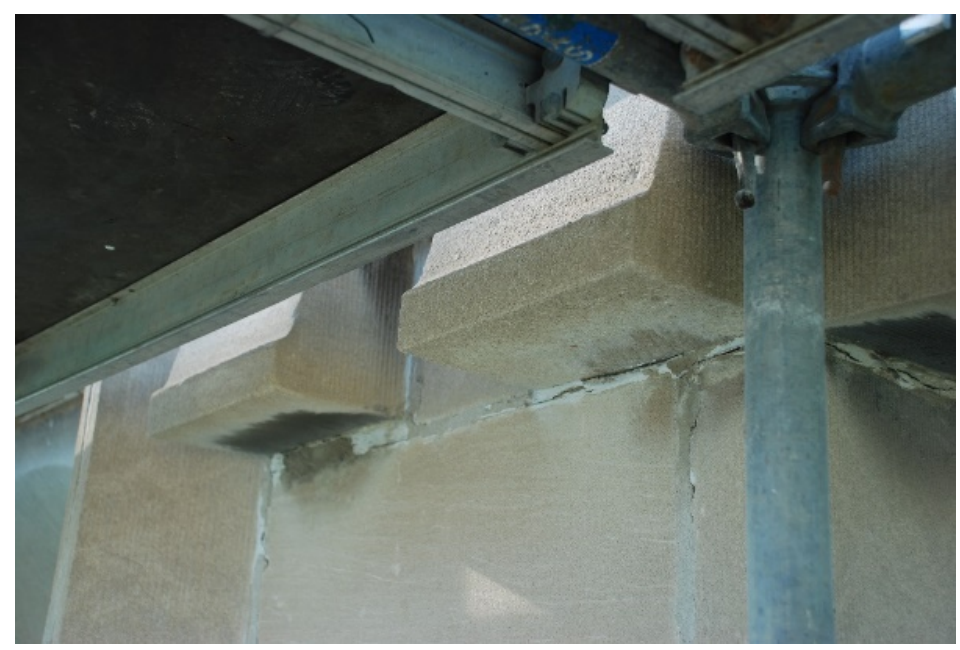

Figure 8: Dental staining.

was rained on causing lime runs. Continued cleaning of the bricks was not approved as the cleaned areas would stand out too prominently from the rest of the building façade and would result in the requirement for the entire bell tower to be cleaned. Also, cleaning the entire bell tower far exceeded the scope of work and would not add any value to the conservation of the building.

With the cleaning completed, all the stonework was re-inspected to determine if any further masonry repairs were required. Further cracks, chips and breaks were discovered so JAHN M70 was used to complete the final repairs to remove any vehicle for water migration into the stones. The last task was completed on the parapet cap stone on the north-east face of the chimney and required a double epoxy pin to complete the stone repair. A special heated hoarding was created to cover this area to allow the repair to properly cure in sub-zero temperatures.

A final inspection was completed on December 2, 2016 allowing the contractor to remove the scaffolding and demobilize from the site

\section{CONCLUSIONS}

Overall, the project was a great success in ensuring the continued viability of the bell tower. The most interesting component was discovering the design differences from the original design to the present rebuilt church and the architectural features that were changed as a result of the tornado. It was also interesting to see how, over time, the redeveloped design became understood to be its original appearance. The most difficult aspect of the project was dealing with the volatility of the weather. Temperatures moved from above zero to below zero within a twenty-four-hour period and the project was subjected to the impacts of multiple freeze thaw cycles throughout the day. To prevent mortar failure, ensuring proper temperatures and humidity were maintained within the construction area of the scaffolding became the most important aspect of the project. The result of the project was that all areas where water migration into the stone or brick and the building envelope could take place, were sealed. Any broken stones that could have fallen to the ground were repaired. These interventions that will prevent spaulding of the stones and bricks have ensured that the bell tower has been 


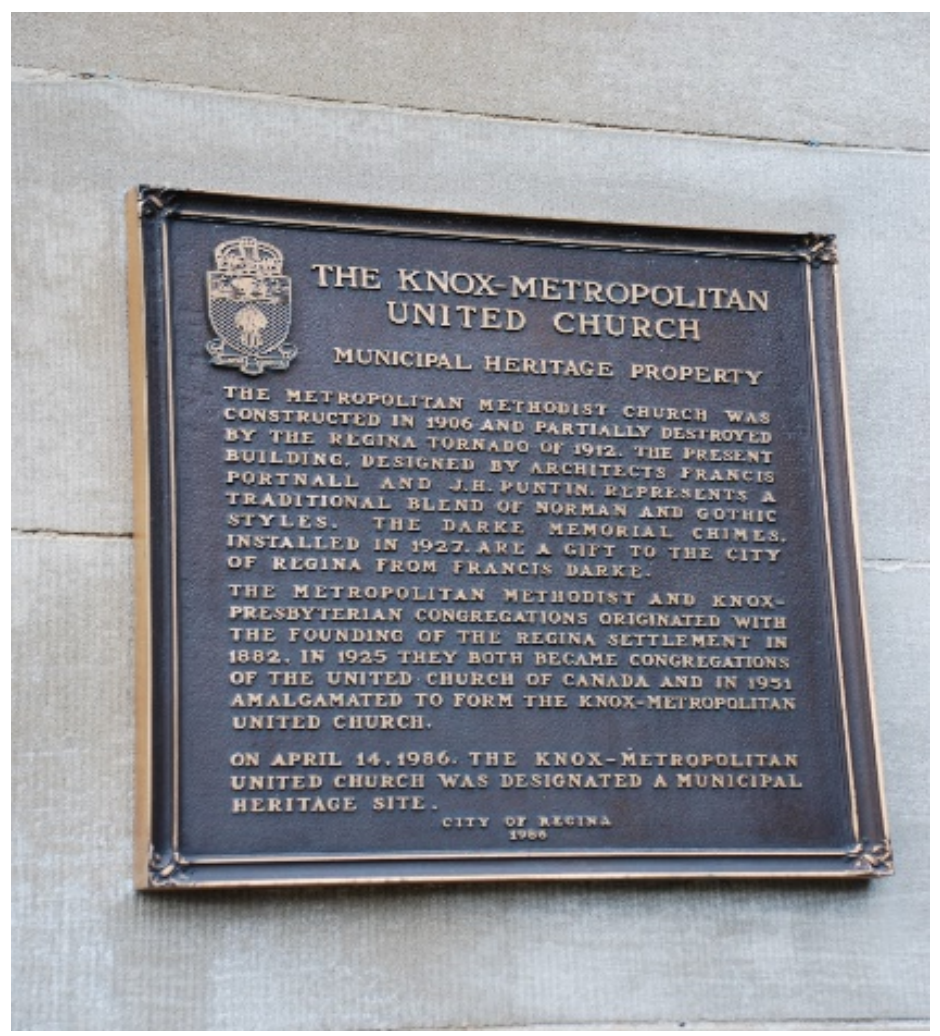

Figure 9: Municipal heritage plaque.

conserved for another 100 years. The church has endured many changes over the years. At the time of the tornado it was called Metropolitan Methodist Church until the name was changed to Knox Metropolitan United Church in 1951. The memorial chimes were installed in 1927. To this day, the church on the corner of Victoria Avenue and Lorne Street remains a hub of the community hosting the Rotary Carol Festival, musical events, workshops and book sales. Conserving a small part of this building will allow it to continue as a vibrant symbol for the community for many years to come (see Fig. 9).

\section{REFERENCES}

[1] Bingaman, S., Storm of the Century. The Regina Tornado of 1912, copyright (C) 2011 Canadian Plans Research Center Press, p. 18.

[2] Bingaman, S., Storm of the Century. The Regina Tornado of 1912, copyright (C) 2011 Canadian Plans Research Center Press, p. 44. 